\title{
MONITOROVANIE VARIÁCIÍ KONTINENTÁLNEHO LADOVCA AUSTFONNA POMOCOU DÁT DRUŽICOVÝCH MISIÍ GRACE A GRACE-FO
}

\author{
AUSTFONNA GLACIER ICE SHEET VARIATION MONITORING USING \\ GRACE AND GRACE-FO DATA
}

Barbora Korekáčová*,1

*barbora.korekacova@stuba.sk

${ }^{1}$ Stavebná fakulta STU v Bratislave, Radlinského 11, 81005 Bratislava

\begin{abstract}
Abstrakt
Družicové misie GRACE a GRACE-FO nám poskytujú dáta vhodné na modelovanie tiažového pol’a Zeme. Hlavným zdrojom variácií tiažového pol'a zachytených misiami GRACE a GRACE-FO je pohyb zemských hmôt. Pre určenie variácií l’adovcových hmôt musíme zachytený gravitačný signál opravit' o kontinentálnu hydrológiu a efekt z postglaciálneho izostatického vyrovnania. Článok sa venuje popisu procesu výpočtu časových variácií kontinentálneho l’adovca Austfonna. Zo 198 globálnych geopotenciálnych modelov misií GRACE a GRACE-FO v kombinácii s hydrologickým modelom GLDAS NOAH a modelom postglaciálneho izostatického vyrovnania založeného na l'adovcovej histórii ICE-5G bol určený časový rad znázorňujúci zmeny kontinentálneho l'adovca Austfonna a jeho kvadratický trend v zmysle ekvivalentnej výšky vodného stlpca.
\end{abstract}

\section{Kl'účové slova}

GRACE, GRACE-FO, kontinentálny l’adovec, postglaciálne izostatické vyrovnanie, globálny hydrologický model

\begin{abstract}
GRACE and GRACE-FO satellite missions provide important data necessary for temporal gravity field variation modelling. The main cause of Earth's gravity field variations monitored by GRACE and GRACE-FO is the motion of Earth masses. To assess the ice mass variations, we have to correct the measured gravity signal for land hydrology variations and effect of post-glacial isostatic rebound. This paper describes the computational process of ice mass variations in Austfonna glacier ice cap. A total of 198 monthly GRACE and GRACE-FO global geopotential models, global hydrological model GLDAS NOAH and GIA model forced with ICE-5G global ice loading history were used to estimate the value of quadratic trend in terms of equivalent water height.
\end{abstract}

Key words

GRACE, GRACE-FO, glacial ice cap, postglacial isostatic rebound, global hydrological model

\section{1 ÚVOD}

Družicová misia GRACE (Gravity Recovery and Climate Experiment) spolu s jej aktuálne prebiehajúcim nástupcom, misiou GRACE-FO (GRACE - Follow On), poskytujú od roku 2002 s približne ročnou prestávkou dáta zachytávajúce variácie tiažového pol’a Zeme.

Obe misie sú tvorené dvojicou družíc (GRACE-A, GRACE-B) ktoré, orbitujúc okolo zemského povrchu, merajú svoju vzájomnú vzdialenost'. Družicový pár reaguje na aktuálne tiažové pole Zeme spomalením alebo zrýchlením najprv jednej a následne druhej družice, čím dochádza k zmenám ich vzájomnej vzdialenosti.

Misia svoju konfiguráciu nad zemským povrchom zopakuje približne každých 30 dní, na základe čoho je možné zostavit' mesačné globálne geopotenciálne modely (d’alej GGM) tiažového pol’a Zeme. Spracovaním mesačných GGM získavame informáciu o mesačných zmenách v tiažovom poli Zeme, ktoré sú spôsobené presunmi hmôt tvoriacimi atmo-, lito- a hydrosféru.

Ciel'om práce je určenie variácií množstva l'adovcovej hmoty na území l’adovcovej oblasti Austfonna pokrývajúcej prevažnú čast' ostrova Nordaustlandet, ktorý je súčast’ou súostrovia Špicbergy. Praktický 
experiment je realizovaný na základe globálnych geopotenciálnych modelov družicových misií GRACE a GRACE-FO s uvážením preurčených hodnôt vybraných sférických harmonických koeficientov, hydrologických parametrov a efektu postglaciálneho izostatického vyrovnania.

\section{GRAVITAČNÝ SIGNÁL DRUŽICOVÝCH MISIÍ GRACE A GRACE-FO}

Aby sme z celkového gravitačného signálu, ktorý družice misie zachytia, získali len náš požadovaný parameter, ktorým je v tomto prípade variácia l'adovcovej hmoty (IMB - Ice Mass Balance), je potrebné vysporiadat' sa so všetkými ostatnými prispievajúcimi parametrami.

Vplyv atmosféry je z meraní misie GRACE odstránený ešte pred tvorbou individuálnych GGM pomocou 6-hodinových meteorologických modelov centra ECMWF (European Centre for Medium-Range Weather Forecast) [1].

Najvýraznejší vplyv litosféry na gravitačný signál zachytený družicami misie GRACE môžeme pozorovat' pôsobením javu, ktorý nazývame postglaciálne izostatické vyrovnanie (Glacial Isostatic Adjustment - GIA). Ide o reakciu elastickej Zeme na postupný úbytok l'adovcov od konca poslednej doby l'adovej, ktorá má lineárny charakter a prejavuje sa najmä v oblasti severnej Kanady, Grónsku, Škandinávii a Antarktíde [2].

Zostávajúce zmeny tiažového pol’a Zeme sú spôsobené variáciami vodného obalu Zeme, teda presunmi kontinentálnej vody, snehu a l'adu. Do výpočtu variácíi l'adovcovej hmoty je preto potrebné zahrnút' aj parametre ako vlhkost' pôdy a množstvo vody obsiahnutej v snehovej pokrývke a vegetácii [2].

\section{KOREKCIE SFÉRICKÝCH HARMONICKÝCH KOEFICIENTOV}

Súčast'ou definície družicových misií GRACE a GRACE-FO je použitie geocentrického súradnicového systému. Jeho začiatok je totožný s dlhodobým priemerom polohy geocentra a sférické harmonické koeficienty prvého stupňa, vyjadrujúce umiestnenie telesa aproximujúceho Zem $\mathrm{v}$ rámci súradnicového systému, sú preto konštantné. Geocentrum ako hmotný stred Zeme však reaguje na presuny zemských hmôt zmenou svojej polohy v čase, čím zároveň dochádza k zmenám koeficientov prvého stupňa. Presuny geocentra (voči jeho fixnej polohe v geocentrickom súradnicovom systéme) je nutné uvážit pri skúmaní javov súvisiacich s pohybom zemských hmôt. Jednou z metód, ktoré sa v súčasnosti využívajú pri monitorovaní polohy geocentra je laserová lokácia družíc (SLR) [3].

Sférický harmonický koeficient $\mathrm{C}_{2,0}$ súvisiaci so sploštením Zeme je družicovými misiami GRACE a GRACE-FO určený s nedostatočnou presnost'ou. Pri spracovaní dát misie GRACE je preto žiaduce jeho nahradenie presnejšie určenými hodnotami. Metódou, ktorá sa pri určovaní koeficientu $\mathrm{C}_{2,0}$ ukázala ako spol’ahlivejšia, je laserová lokácia družíc [4].

Rovnako aj v prípade koeficientu $\mathrm{C}_{3,0}$ je vhodné nahradit' ho hodnotami určenými pomocou SLR. Dôvodom jeho nedostatočne presného určenia misiami GRACE alebo GRACE-FO sú výpadky vo fungovaní akcelerometrov na družiciach. $\mathrm{S}$ dostačujúcou presnost'ou však mohol byt' sférický harmonický koeficient $\mathrm{C}_{3,0}$ určený až po štarte družicovej misie LARES v roku 2012. Zavedenie korekcií koeficientu $\mathrm{C}_{3,0}$ je dôležité najmä pri výpočtoch v oblasti Antarktídy [4].

\section{DÁTA A METÓDY}

Predmetom praktického experimentu bolo určenie variácií množstva l'adovcovej hmoty na území l'adovcovej oblasti Austfonna (Obr. 1). Ide o l’adovcovú oblast' pokrývajúcu prevažnú väčšinu ostrova Nordaustlandet, ktorý je súčast'ou súostrovia Špicbergy, o rozlohe približne 7050 km².

Sférický harmonický koeficient $\mathrm{C}_{2,0}$ súvisiaci so sploštením Zeme je družicovými misiami GRACE a GRACE-FO určený s nedostatočnou presnost'ou. Pri spracovaní dát misie GRACE je preto žiaduce jeho nahradenie presnejšie určenými hodnotami. Metódou, ktorá sa pri určovaní koeficientu $\mathrm{C}_{2,0}$ ukázala ako spol'ahlivejšia, je laserová lokácia družíc [4].

Pri zmene koeficientov $\mathrm{C}_{2,0}$ a $\mathrm{C}_{3,0}$ bol použitý súbor koeficientov NASA GSFC SLR C20 and C30 solutions [4], ktoré sú určené na základe laserovej lokácie družíc LAGEOS-1, LAGEOS-2, Stella, Starlette, AJISAI, Lares a Larets [4]. Koeficienty $\mathrm{C}_{2,0}$ sú dostupné pre celé obdobie trvania misií GRACE a GRACE-FO, koeficienty $\mathrm{C}_{3,0}$ 
sú dostupné od roku 2012 (kapitola 3) a sú aktualizované s pribúdajúcimi mesačnými geopotenciálnymi modelmi GRACE-FO.

Korekcia z postglaciálneho izostatického vyrovnania bola zavedená na základe frekventovane použivaného modelu od Geruo, A. [7]. Jedným z produktov [7] sú aj hodnoty korekcie z postglaciálneho izostatického vyrovnania prepočítané na hodnoty výšky vodného stlpca.

Hydrologické parametre vlhkost' pôdy (SM - Soil Moisture), množstvo vody ekvivalentné snehovej pokrývke (SWE - Snow Water Equivalent) a množstvo vody obsiahnuté vo vegetácii (CAN - Canopy Water Storage) sú súčast'ou mesačných hydrologických modelov GLDAS NOAH Land Surface Model [8] s priestorovým rozlíšením $0.25^{\circ} \times 0.25^{\circ}$.

Výsledky výpočtov boli orezané podl'a hraníc kontinentálnych l’adovcov, ktoré sú súčast’ou Randolph Glacier Inventory 6.0 a sú dostupné na webovej stránke [9] vo formáte shapefile.

Prvým krokom bol výpočet variácií celkovej ekvivalentnej výšky vodného stĺpca v zvolenom území ( $\Delta$ TWS - Total Water Storage), ktoré boli určené vzhl'adom k zvolenému referenčnému modelu. Za referenčný model bol použitý GGM misie GRACE prislúchajúci júlu 2011. Výpočet $\Delta$ TWS bol vykonaný podl'a vzt'ahu (14) uvedenom v [10] v prostredí softvéru GrafLab [11].

Variácie l'adovcovej hmoty $\triangle \mathrm{IMB}$ boli určené odčítaním všetkých spomenutých parametrov od hodnôt $\triangle T W S$ určených z družicových misií GRACE a GRACE-FO. Veličina $\triangle I M B$ je uvádzaná v zmysle výšky vodného stípca, t.z. že zmena objemu l'adovca je vyjadrená prostredníctvom zmeny výšky vodného stĺpca vody, ktorá by vznikla roztopením l'adovca, na jednotku plochy. Výpočty boli vykonané na základe pôvodných, nezmenených modelov s originálnymi sférickými harmonickými koeficientmi poskytovanými službou ICGEM [5] a následne zopakované po zmene sférických harmonických koeficientov (d’alej $\mathrm{SHK}$ ) $\mathrm{C}_{1,0}, \mathrm{C}_{1,1}, \mathrm{~S}_{1,1}, \mathrm{C}_{2,0}$ a $\mathrm{C}_{3,0}$. Relatívne zmeny boli určené vzhl'adom k statickému modelu GGM05C [12]. Z variácií l'adovcovej hmoty bol odhadnutý kvadratický koeficient charakterizujúci zmenu ich množstva.

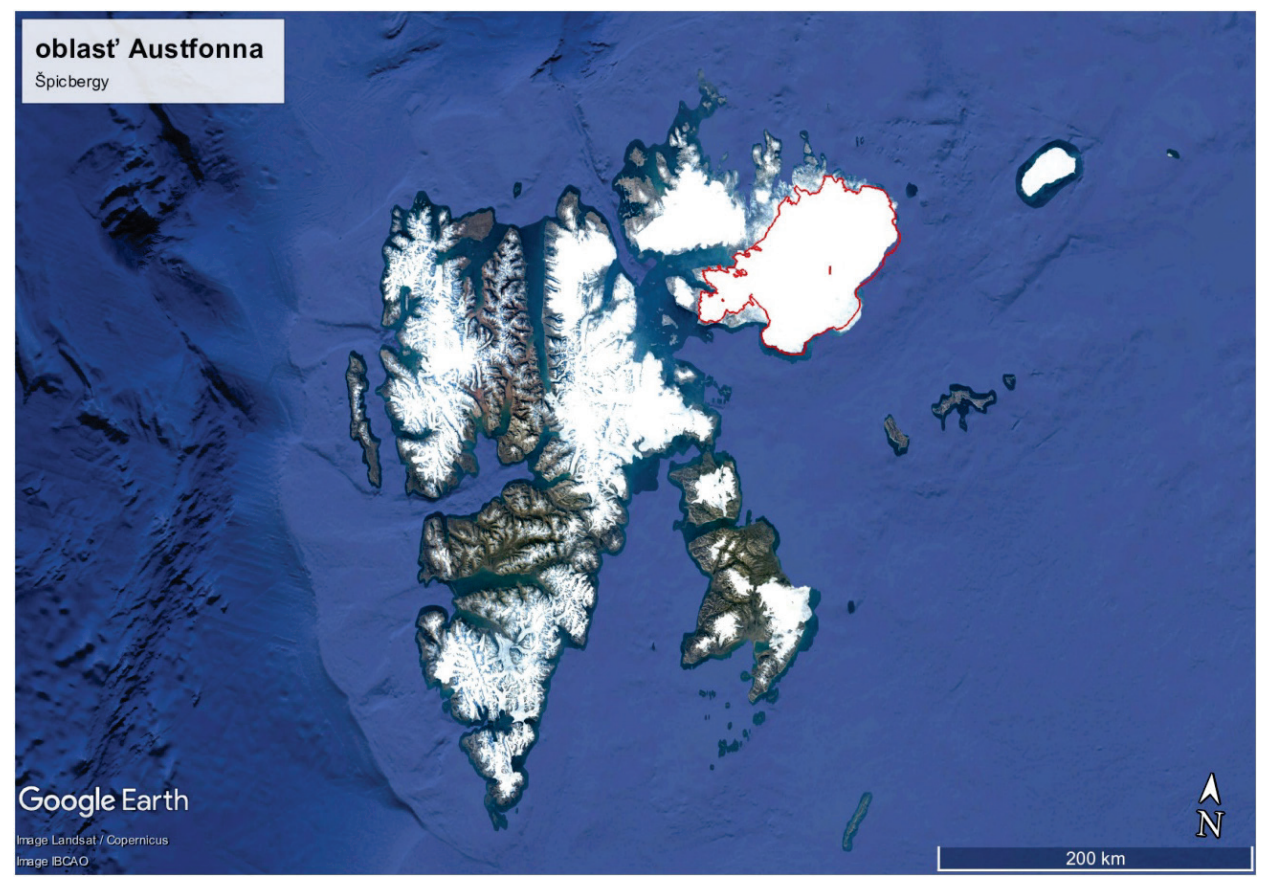

Obr. 1 Ladovcová oblast' Austfonna.

\section{VÝSLEDKY EXPERIMENTU}

Na základe dát modelov družicových misií GRACE a GRACE-FO boli vypočítané variácie celkovej výšky vodného stípca v záujmovej oblasti. Výpočet bol najprv vykonaný z pôvodných, nezmenených dát (Obr. 2a) potom $\mathrm{z}$ dát $\mathrm{s}$ opravenými sférickými harmonickými koeficientmi (Obr. 2a). Rozdiely vo variáciách celkovej výšky vodného stĺpca spôsobené zmenou SHK sa pohybujú na úrovni od -12,7 po 5,4 cm. (Obr. 2b). 
8. Geodézie, kartografie a geoinformatika

JUNIORSTAV 2022
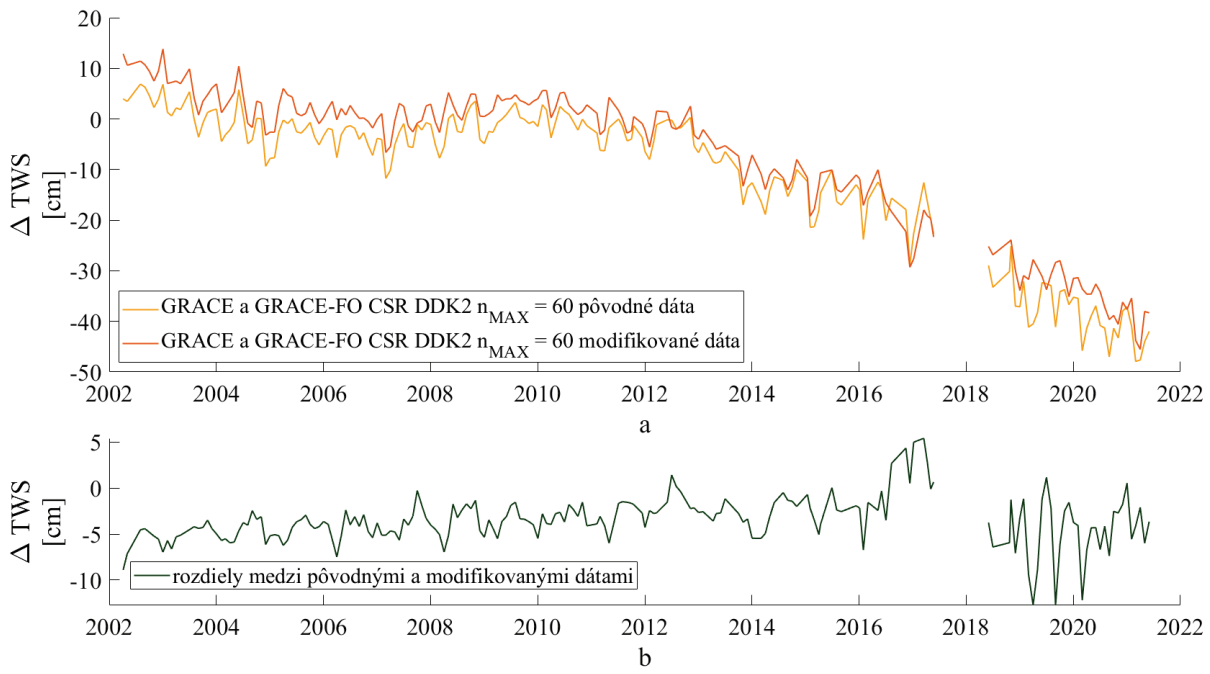

Obr. 2 a) Priebeh hodnôt celkovej výšky vodného stĺpca vypočítaných z modelov GRACE a GRACE-FO z pôvodných a modifikovaných dát, b) Rozdiely medzi priebehom zmien TWS určeným z pôvodných a z modifikovaných dát.

Z modelu Geruo, A. [7], ktorý GIA korekciu prepočítava na výšku vodného stĺpca, bola pre l'adovcovú oblast' Austfonna určená korekcia efektu postglaciálneho izostatického vyrovnania na úrovni $0,82 \mathrm{~cm} / \mathrm{rok}$ (Obr. 3).

Z modelu GLDAS NOAH [8] boli určené hodnoty mesačných zmien hydrologických parametrov CAN, SWE a SM vzhl'adom k ich dlhodobému priemeru (určeného z rokov 2002 - 2021), pohybujúce sa na úrovni od -6 do $4 \mathrm{~cm} /$ mesiac (Obr. 3).

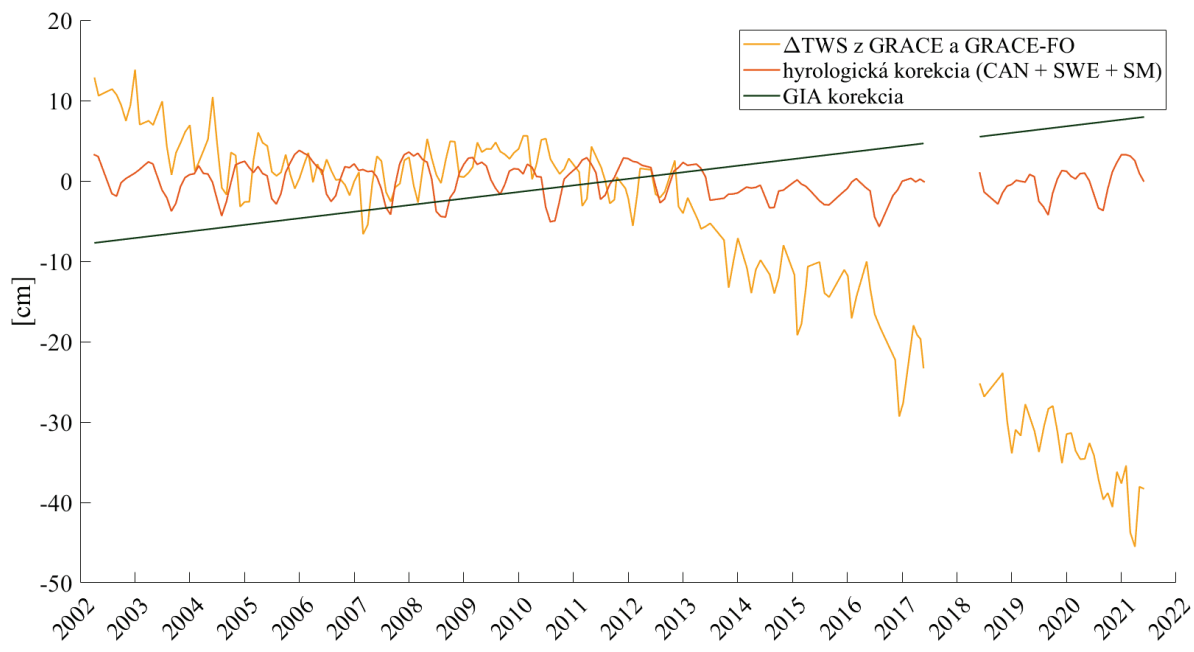

Obr. 3 Priebeh $\Delta$ TWS po uvážení zmien SHK, hydrologickej a GIA korekcie.

http://dx.doi.org/10.13164/juniorstav.2022.628

631 


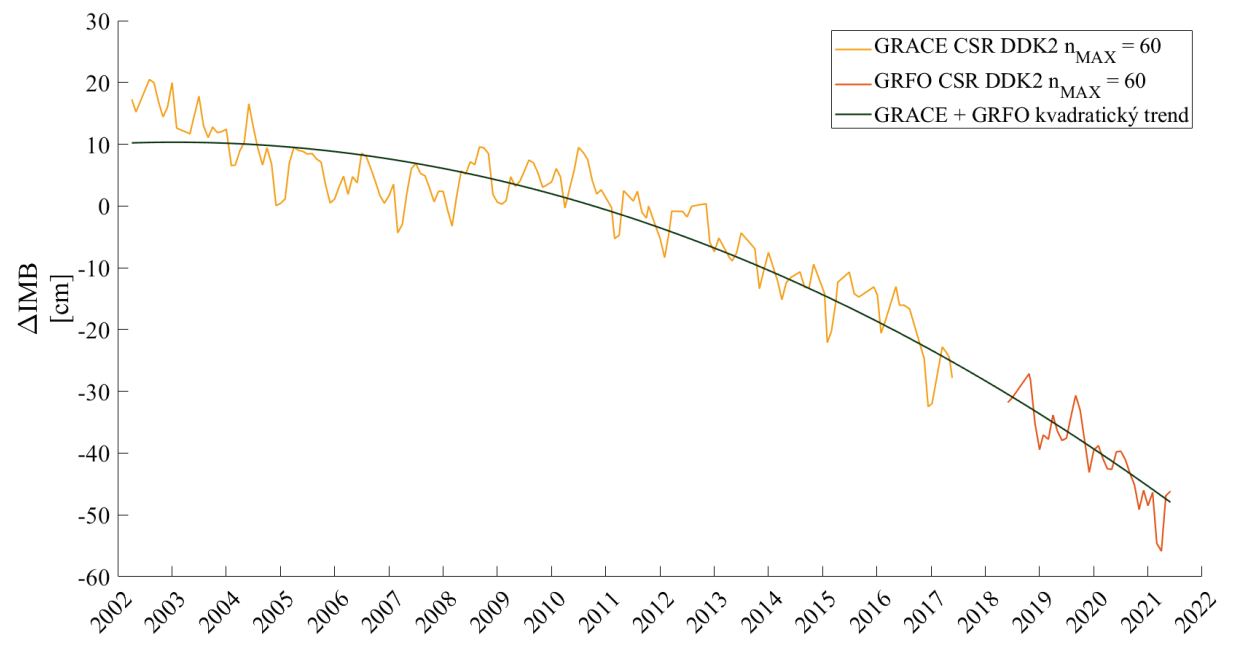

Obr. 4 Priebeh variácií l'adovcovej hmoty v l'adovcovej oblasti Austfonna.

Variácie l’adovcovej hmoty v záujmovej oblasti po odčítaní GIA korekcie a hydrologických parametrov dosahujú hodnoty od -55,9 do 20,5 cm výšky vodného stĺpca (Obr. 4). Z variácií l'adovcovej hmoty bol pomocou regresnej analýzy odhadnutý regresný polynóm druhého stupňa charakterizovaný rovnicou (1).

$$
\Delta I M B(t)=-0.17 x^{2}+691.64 x-69268.29_{s}
$$

\section{ZÁVER}

Práca sa zaoberá určením variácií množstva l'adovcovej hmoty na území l'adovcovej oblasti Austfonna, ktoré pokrýva ostrov súostrovia Špicbergy. Vybrané sférické harmonické koeficienty určené z meraní družicových misií GRACE a GRACE-FO boli nahradené odhadnutými hodnotami získanými pomocou laserovej lokácie družíc, ktoré poskytujú reálnejší pohl'ad na ich zmeny. Modifikácia sférických harmonických koeficientov $\mathrm{v}$ riešenom území zmenila priebeh variácií celkovej výšky vodného stĺpca o hodnoty od $-12,7$ po $5,4 \mathrm{~cm}$. Odpočítaním hydrologických parametrov vyjadrujúcich množstvo vody obsiahnuté v snehovej pokrývke, vegetácii a pôde a efektu z postglaciálneho izostatického vyrovnania boli určené mesačné zmeny l'adovcovej hmoty na úrovni $-55,8$ až 20,5 cm v zmysle výšky vodného stĺpca. Z variácí l'adovcovej hmoty bol pomocou regresnej analýzy odhadnutý kvadratický trend -0,173 cm/rok2 vyjadrujúci zmenu ročného úbytku.

\section{Pod'akovanie}

Tento článok vznikol s podporou grantovej agentúry VEGA v rámci riešenia projektu VEGA 1/0809/21: Spoločné vyhodnotenie variácie vodných hmôt a l'adovej pokrývky na základe dát družicových misií GRACE, SWARM a GRACE-FO.

\section{Použité zdroje}

[1] GRACE Level-1B Atmosphere and Ocean De-aliasing Product (GRACE AOD1B). GFZ German Research Centre for Geosciences. [cit. 2021-9-27].

Dostupné z: https://www.gfz-potsdam.de/en/aod1b/

[2] SWENSON, Sean, John WAHR a P. C. D. MILLY. Estimated accuracies of regional water storage variations inferred from the Gravity Recovery and Climate Experiment (GRACE). Water Resources Research [online]. 2003, 39(8) [cit. 2021-9-27]. ISSN 00431397.

Dostupné z: doi:10.1029/2002WR001808

[3] SUTTERLEY, Tyler C. a Isabella VELICOGNA. Improved Estimates of Geocenter Variability from Time-Variable Gravity and Ocean Model Outputs. Remote Sensing [online]. 2019, 11(18)

[cit. 2021-9-27]. ISSN 2072-4292. Dostupné z: doi:10.3390/rs11182108 
[4] LOOMIS, Bryant D., Kenneth E. RACHLIN, David N. WIESE, Felix W. LANDERER a Scott B. LUTHCKE. Replacing GRACE/GRACE-FO With Satellite Laser Ranging: Impacts on Antarctic Ice Sheet Mass Change. Geophysical Research Letters [online]. 2020, 47(3) [cit. 2021-9-27]. ISSN 0094-8276. Dostupné z: doi:10.1029/2019GL085488

[5] INCE, E. Sinem, Franz BARTHELMES, Sven REISSLAND, Kirsten ELGER, Christoph FÖRSTE, Frank FLECHTNER a Harald SCHUH. ICGEM - 15 years of successful collection and distribution of global gravitational models, associated services, and future plans. Earth System Science Data [online]. 2019, 11(2), 647-674 [cit. 2021-9-27]. ISSN 1866-3516. Dostupné z: doi:10.5194/essd-11-647-2019

[6] Geocenter Estimates from Time-Variable Gravity and Ocean Model Outputs. [cit. 2021-9-27]. Dostupné z: https://figshare.com/articles/dataset/Geocenter_Estimates_from_TimeVariable_Gravity_and_Ocean_Model_Outputs/7388540? file $=304198 \overline{23}$

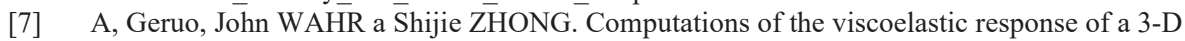
compressible Earth to surface loading: an application to Glacial Isostatic Adjustment in Antarctica and Canada. Geophysical Journal International [online]. 2012, 192(2), 557-572 [cit. 2021-9-27]. ISSN 0956-540X. Dostupné z: doi:10.1093/gji/ggs030

[8] RODELL, M., P. R. HOUSER, U. JAMBOR, et al. The Global Land Data Assimilation System. Bulletin of the American Meteorological Society [online]. 2004, 85(3), 381-394 [cit. 2021-9-27]. ISSN 0003-0007. Dostupné z: doi:10.1175/BAMS-85-3-381

[9] RGI Consortium (2017). Randolph Glacier Inventory - A Dataset of Global Glacier Outlines: Version 6.0: Technical Report, Global Land Ice Measurements from Space, Colorado, USA. Digital Media. [cit. 2021-9-27]. Dostupné z: https://doi.org/10.7265/N5-RGI-60

[10] WAHR, John, Mery MOLENAAR a Frank BRYAN. Time variability of the Earth's gravity field: Hydrological and oceanic effects and their possible detection using GRACE. Journal of Geophysical Research: Solid Earth [online]. 1998, 103(B12), 30205-30229 [cit. 2021-9-27]. ISSN 01480227. Dostupné z: doi:10.1029/98JB02844

[11] BUCHA, Blažej a Juraj JANÁK. A MATLAB-based graphical user interface program for computing functionals of the geopotential up to ultra-high degrees and orders. Computers \& Geosciences [online]. 2013, 56, 186-196 [cit. 2021-9-27]. ISSN 00983004. Dostupné z: doi:10.1016/j.cageo.2013.03.012

[12] RIES, J., BETTADPUR, S., EANES, R., KANG, Z., KO, U., MCCULlOUGH, C., NAGEL, P., PIE, N., POOLE, S., RICHTER, T., SAVE, H., TAPLEY, B. (2016): The Combined Gravity Model GGM05C. GFZ Data Services. [cit. 2021-9-27]. Dostupné z: https://doi.org/10.5880/icgem.2016.002 